\title{
AHP-TOPSIS-Based Evaluation of the Relative Performance of Multiple Neighborhood Renewal Projects: A Case Study in Nanjing, China
}

\author{
Shiyao Zhu ${ }^{1}$, Dezhi $\mathrm{Li}^{1,2, *}$, Haibo Feng ${ }^{3}$, Tiantian Gu ${ }^{1}$ 他 Jiawei Zhu ${ }^{1}$ \\ 1 School of Civil Engineering, Southeast University, Nanjing 211189, China \\ 2 Engineering Research Center of Building Equipment, Energy, and Environment, Southeast University, \\ Nanjing 211189, China \\ 3 School of Engineering, University of British Columbia, 1137 Alumni Ave, Kelowna, BC V1V 1V7, Canada \\ * Correspondence: njldz@seu.edu.cn
}

Received: 2 August 2019; Accepted: 16 August 2019; Published: 21 August 2019

\begin{abstract}
With the rapid development of urbanization worldwide, there is a large volume of neighborhoods that need to be renewed with various problems such as poor building performance, few public facilities, congested road traffic, unequal living standards, disappearing community culture, and deprived environments. Performance evaluations are considered to be useful tools for ensuring the outcomes of sustainable renewal. Although many research works have assessed the performances of urban renewal projects, evaluations, especially for neighborhood renewal projects, are often overlooked. Besides, it is also hard to find a general standard that is suitable for evaluating the performance of any neighborhood renewal project with a lack of related regulations or codes. Thus, this paper intends to build a framework to assess the relative performances of multiple neighborhood renewal projects through a hybrid AHP-TOPSIS method. A case study in Nanjing, China, is used to show how this framework could be applied to decision-making in order to pursue sustainable neighborhood renewal. The results are expected to provide references for sustainable renewal in each neighborhood. Suggestions related to the findings are proposed to further improve the performances of neighborhood renewal projects, such as establishing a multiple principle-agent framework, providing a sustainable funding system from both the public and private sector, and implementing multiprogram management measures.
\end{abstract}

Keywords: neighborhood renewal; AHP-TOPSIS method; performance evaluation; old neighborhood

\section{Introduction}

Urban renewal has been recognized as a major approach to promoting land values and improving the quality of the environment and human life [1]. Considering the large concentration of the population and the significant proportion of cities, neighborhoods are considered to be at the microscopic level of urban renewal [2,3]. Neighborhood renewal, also called neighborhood regeneration, neighborhood redevelopment, or neighborhood rehabilitation, is a derivation from urban renewal that seeks to improve the condition of neighborhoods from sustainable viewpoints through the integration of peopleand place-based strategies. It was introduced in developed countries in the 1990s with final goals of ensuring that local communities are willing to live and work in neighborhoods in the present and future [4].

Various kinds of neighborhoods have been renewed in both developed and developing countries with different focuses, e.g., disadvantaged neighborhoods in France and the Netherlands $[5,6]$, poor neighborhoods in America [7], deprived neighborhoods in Israel [8], historic areas in Turkey [9], 
low-income neighborhoods in Denmark [10], deteriorated communities in Korea [2], and neighborhoods after natural hazards in Japan [11]. Mainly topics are related to urban decline, safety, health, gentrification, or public participation during the renewal process.

Meanwhile, neighborhood renewal in China mainly refers to the physical rehabilitation of old residential neighborhoods, also called old neighborhood renewal (ONR). With the accelerating pace of urbanization in China, a large number of newly built neighborhoods with multiple supporting facilities and comfortable environments have merged to continuously improve the living quality of urban residents [12]. At the same time, there are still a large number of old neighborhoods built before 2000 in downtown areas of urban China, which are the shortcomings of urban development and are usually uncoordinated with nearby newly built neighborhoods [13]. Those old neighborhoods are mainly residential neighborhoods, which generally have particular characteristics of a long development history, poor living quality, and dirty environment that cannot even meet people's normal living needs $[3,14]$.

The outcomes of the renewal projects are discussed a lot by conducting performance evaluations. This refers to a systematic process in which an organization intends to accomplish certain goals, plans how to achieve the goal, and assesses whether the organization has accomplished its goal [15]. The evaluation can help stakeholders to improve their strategies or solutions in order to achieve the most sustainable outcomes $[16,17]$. Some national assessment tools have been developed and have been commonly in use over the years to promote the high performance of neighborhoods in developed countries [18-20], e.g., the Leadership in Energy and Environmental Design for Neighborhood Development (LEED-ND, US), the Building Research Establishment Environmental Assessment Method for Communities (BREEAM Communities, UK) and the Comprehensive Assessment System for Building Environmental Efficiency for urban development (CASBEE UD, Japan). However, those methods are structured according to local requirements, in which the objectives, evaluation criteria, and sustainable indexes are verily defined [20].

As for research, the indicator-based approach has attracted the most attention in the urban context for performance evaluations [21]. For example, Hemphill et al. (2004) developed an indicator-based approach for urban renewal evaluation with qualitative discussion and quantitative assessment [22]. Peng et al. (2015) proposed an alternative model for measuring the sustainability of urban regeneration with indicators considering building performance, environmental, social, and economic development [23]. Riera et al. (2018) developed an indicator system for measuring sustainable neighborhood renewal from six objectives, including ensuring viability, balancing supply, saving energy resources, and upgrading the local environment [24]. Li et al. (2016) assessed the performance of public involvement for sustainable urban regeneration based on indicators of inclusivity, equality, transparency, and interactivity [25].

However, most assessment tools worldwide have been focused on the urban scale or the sustainability of the neighborhood, and performance evaluations specifically for neighborhood renewal projects are limited $[21,26]$. The methods used are mainly subjective evaluations with judgements from experts or questionnaires from the public. There is a lack of quantitative evaluation for the performance of neighborhood renewal projects based on actual situation data. Besides, many of the renewal projects are ad hoc projects without long-term planning, and the sustainability of the renewal outcomes remains a question $[13,27]$. Consequently, many renewed neighborhoods are suffering a "return-back" scenario, which means the neighborhoods will return to their poor situation before the regeneration. This fails to meet the initial objective of neighborhood renewal, i.e., to improve, maintain, and upgrade the living environment and life qualities of an entire nation [17]. Thus, it is vital to evaluate the holistic performance of these projects after the renewal in order to establish long-term guidelines for urban renewal polices.

Moreover, with a lack of related regulations or codes, it is hard to find a general standard that is suitable for evaluating the performance of any neighborhood renewal project. It is relatively easier to evaluate and compare the advantages of different neighborhood renewal projects. The technique 
for order preference through similarity to an ideal solution (TOPSIS) is a common method used in multiple criteria decision-making (MCDM). It has proven efficient in the evaluation of the relative merits of existing objects for many years [28,29]. Thus, considering the gap in existing studies, this paper tries to provide a comprehensive framework for measuring the relative performance of multiple neighborhood renewal projects with the following objectives: (a) to identify the performance indicators assessing the neighborhood renewal projects; (b) to establish a framework for relative performance evaluations of neighborhood renewal projects through the AHP-TOPSIS method; (c) to conduct an empirical analysis by evaluating the performance of ONR projects in Nanjing, China; and (d) to provide recommendations that will help improve the long-term governance of neighborhoods with existing and future neighborhood renewal projects.

\section{Methodology}

This paper developed a methodology to fill the gap in existing studies by measuring the relative performances of multiple neighborhood renewal projects with a case study of ONR projects in China. As illustrated in Figure 1, the developed procedures for measuring the performance of neighborhood renewal projects are given in the following steps:

Step 1. Identify the criteria for the performance evaluation of neighborhood renewal projects through a literature review;

Step 2. Find the indicators that can be quantified under each criterion through a literature review and semi-structured interviews;

Step 3. Weight values between the indicators through an analytic hierarchy process (AHP) method;

Step 4. Evaluate the performance of ONR projects through TOPSIS by calculating the positive and negative ideal solutions and ranking the projects.
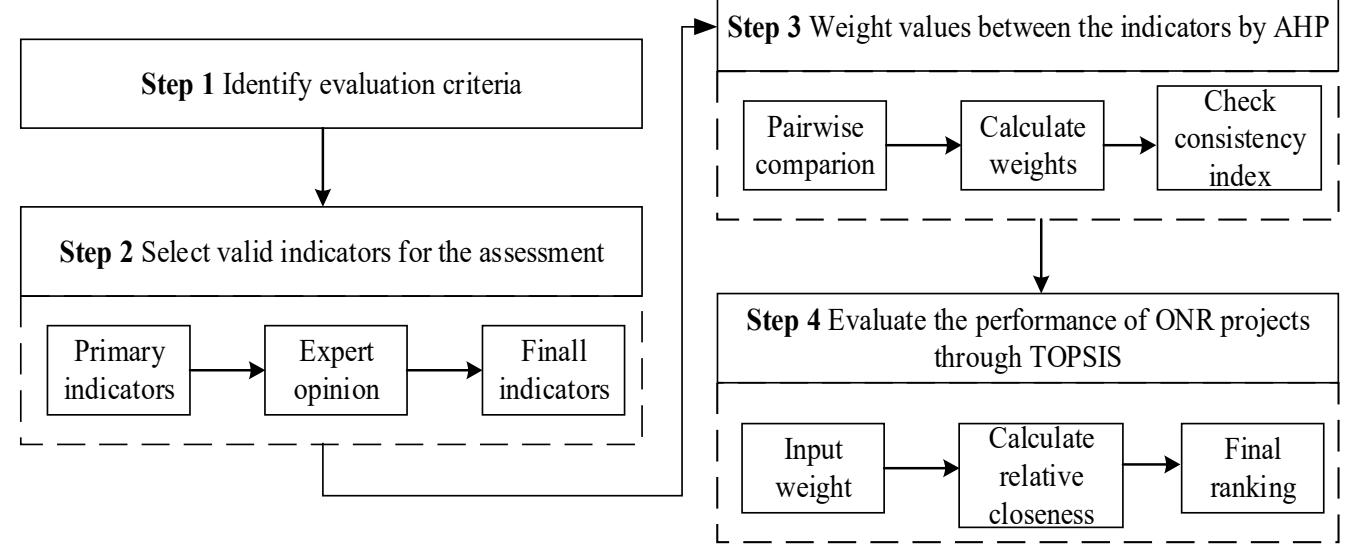

Figure 1. The flow chart of the proposed methodology.

\subsection{Identification of Performance Criteria as a Basis for Assessment}

Different studies on renewal projects with various research scales and evaluation dimensions are summarized in Table 1 (literature review). It is easy to find out from the table that economic, environmental, and social impacts and buildings are four major dimensions that are discussed in renewal projects at high frequencies. The economy, the environment, and society are three pillar aspects of sustainable development [30]. Many researchers have examined the impact of urban renewal by evaluating economic viability, local environment upgrading, and the balance between density and urban quality $[1,24,31]$. Physical rehabilitation for buildings is also important in renewal projects to improve residents' housing welfare and promote community development, which enables the extension of building lifespans, improves living quality, and increases property values [4]. 
Table 1. Summary of studies on renewal evaluation with different categories.

\begin{tabular}{|c|c|c|c|c|c|c|c|c|c|}
\hline \multirow[b]{2}{*}{ Scale } & \multicolumn{8}{|c|}{ Category } & \multirow[b]{2}{*}{ Source } \\
\hline & 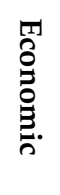 & 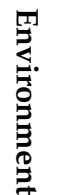 & $\begin{array}{l}\mathscr{L} \\
\stackrel{0}{0} \\
0 .\end{array}$ & 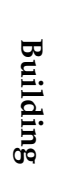 & 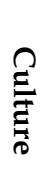 & & 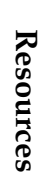 & 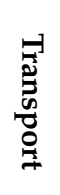 & \\
\hline Urban area & $\mathrm{Y}$ & $\mathrm{Y}$ & $\mathrm{Y}$ & $\mathrm{Y}$ & $\mathrm{N}$ & $\mathrm{Y}$ & $\mathrm{Y}$ & $\mathrm{Y}$ & [22] \\
\hline Traditional old urban area & Y & Y & Y & $\mathrm{Y}$ & $\mathrm{N}$ & $\mathrm{N}$ & $\mathrm{N}$ & $\mathrm{N}$ & [3] \\
\hline Inner city neighborhoods & $\mathrm{Y}$ & $\mathrm{Y}$ & $\mathrm{Y}$ & $\mathrm{N}$ & $\mathrm{N}$ & $\mathrm{N}$ & $\mathrm{N}$ & $\mathrm{N}$ & {$[32]$} \\
\hline Inner urban area & $\mathrm{Y}$ & $\mathrm{Y}$ & $\mathrm{Y}$ & $\mathrm{N}$ & $\mathrm{N}$ & $\mathrm{N}$ & $\mathrm{N}$ & $\mathrm{N}$ & [33] \\
\hline Peri-urban area & Y & Y & $\mathrm{Y}$ & $\mathrm{N}$ & Y & $\mathrm{N}$ & $\mathrm{N}$ & $\mathrm{Y}$ & {$[34]$} \\
\hline Black neighborhood & $\mathrm{N}$ & $\mathrm{N}$ & $\mathrm{Y}$ & $\mathrm{N}$ & $\mathrm{N}$ & $\mathrm{N}$ & $\mathrm{N}$ & $\mathrm{N}$ & [35] \\
\hline Deteriorated urban area & $\mathrm{Y}$ & $\mathrm{Y}$ & $\mathrm{Y}$ & $\mathrm{Y}$ & $\mathrm{N}$ & $\mathrm{N}$ & $\mathrm{N}$ & $\mathrm{N}$ & [23] \\
\hline Old urban area & Y & $\mathrm{Y}$ & $\mathrm{Y}$ & $\mathrm{N}$ & $\mathrm{Y}$ & $\mathrm{N}$ & $\mathrm{N}$ & $\mathrm{N}$ & {$[36]$} \\
\hline Urban area & Y & $\mathrm{Y}$ & $\mathrm{Y}$ & $\mathrm{N}$ & $\mathrm{Y}$ & $\mathrm{N}$ & $\mathrm{N}$ & $\mathrm{N}$ & [37] \\
\hline Urban area & Y & $\mathrm{Y}$ & Y & $\mathrm{N}$ & $\mathrm{N}$ & $\mathrm{N}$ & $\mathrm{N}$ & $\mathrm{N}$ & [15] \\
\hline Abandoned urban area & $\mathrm{Y}$ & $\mathrm{Y}$ & $\mathrm{Y}$ & $\mathrm{N}$ & $\mathrm{N}$ & $\mathrm{N}$ & $\mathrm{N}$ & $\mathrm{Y}$ & [38] \\
\hline Urban area & Y & Y & $\mathrm{Y}$ & $\mathrm{Y}$ & $\mathrm{N}$ & Y & $\mathrm{Y}$ & $\mathrm{N}$ & [1] \\
\hline $\begin{array}{l}\text { Low-income } \\
\text { neighborhood }\end{array}$ & $\mathrm{N}$ & $\mathrm{N}$ & $\mathrm{Y}$ & $\mathrm{N}$ & $\mathrm{N}$ & $\mathrm{N}$ & $\mathrm{N}$ & $\mathrm{N}$ & [39] \\
\hline Deteriorated community & $\mathrm{N}$ & $\mathrm{N}$ & $\mathrm{Y}$ & $\mathrm{Y}$ & $\mathrm{N}$ & $\mathrm{N}$ & $\mathrm{N}$ & $\mathrm{N}$ & [2] \\
\hline Urban neighborhood & $\mathrm{Y}$ & $\mathrm{Y}$ & $\mathrm{Y}$ & $\mathrm{Y}$ & $\mathrm{N}$ & Y & $\mathrm{Y}$ & $\mathrm{N}$ & [24] \\
\hline Frequency & 12 & 12 & 15 & 6 & 3 & 3 & 3 & 3 & \\
\hline
\end{tabular}

Note: Y means that the specific source applies to this category. $\mathrm{N}$ means that the specific source did not use this category.

\subsection{Selection of the Performance Indicators for ONR Project Evaluations}

As for the indicators from the four major dimensions in Table 2, economic indicators are mainly related to financial investment, cost of the project, and changes in housing prices or local economic activities [35]. Environmental indicators refer to physical facilities, waste management, air pollution, and resource consumptions [22,23]. Social indicators care about the public involvement and community cohesion, such as safety, health, participation, satisfaction, and equality [2,35,39-41]. Indicators for the building category are mainly related to the redevelopment of buildings themselves. Primary indicators of the four major categories for assessments are summarized in Table 2.

Table 2. Primary indicators for the evaluation of renewal projects in major categories.

\begin{tabular}{clc}
\hline Category & \multicolumn{1}{c}{ Indicators } & Source \\
\hline \multirow{2}{*}{ Economic } & $\begin{array}{l}\text { House price change rate, commercial change rate, number of } \\
\text { jobs created, construction costs, ratio of renewal reward, } \\
\text { postrenewal value, investment costs and resources, profitability }\end{array}$ & {$[15,35,36]$} \\
\hline \multirow{2}{*}{ Environment } & $\begin{array}{l}\text { Green space change rate, landscaping, waste reduction, parking } \\
\text { area, public area, acoustic emissions, resource consumption, } \\
\text { waste minimization, average emissions of noise per day, road } \\
\text { widening area }\end{array}$ & {$[18,35,42]$} \\
\hline \multirow{2}{*}{ Social } & $\begin{array}{l}\text { Community group involvement, accessibility, gentrification, } \\
\text { public safety, social harmony, social participation, resident } \\
\text { satisfaction, happiness, community service, social cohesion, } \\
\text { racial equality, community health, property management, } \\
\text { frequency of crime }\end{array}$ & {$[22,27,36,38,43,44]$} \\
\hline \multirow{2}{*}{ Buildings } & $\begin{array}{l}\text { Newly built buildings, demolition area, renewal building area, } \\
\text { energy efficiency, reclamation of building materials }\end{array}$ & {$[13,22,23]$} \\
\hline
\end{tabular}


Then, eight experts with at least five years of experience in urban/neighborhood renewal were interviewed and were requested to score the indicators during August to October 2018. Among them, six were officers from the Housing Security and Real Estate Bureau, the Building Real Estate and Transportation Bureau, and the Community Street Office in Beijing, Shanghai, and Nanjing; and another two were researchers from the university. The set of indicators was adjusted by the experts based on their importance as well as the availability and accessibility of the data. The final 13 indicators are shown in Table 3 with their justifications.

Table 3. Performance indicators for neighborhood renewal projects.

\begin{tabular}{|c|c|c|c|}
\hline Indicators & Description & Effect & Justification \\
\hline \multicolumn{4}{|c|}{ Social Performance $(S P)$} \\
\hline SP1: safety status & Frequency of crimes & Negative & [43] \\
\hline$S P 2$ : residents' participation & $\begin{array}{l}\text { Number of residents' meetings for } \\
\text { the project under investigation }\end{array}$ & Positive & {$[22,23]$} \\
\hline SP3: residents' perception & $\begin{array}{l}\text { Residents' complaints after } \\
\text { renewal construction for the } \\
\text { project under investigation }\end{array}$ & Negative & {$[18,22]$} \\
\hline \multicolumn{4}{|c|}{ Economic Performance $(E c P)$} \\
\hline$E c P 1$ : long-term governance & $\begin{array}{c}\text { Introducing property } \\
\text { management }\end{array}$ & Positive & {$[13,27]$} \\
\hline$E c P 2$ : house values & House prices change rate & Positive & {$[24,42]$} \\
\hline \multicolumn{4}{|c|}{ Environmental Performance $(E n P)$} \\
\hline EnP1: environmental quality improvement & Green space change rate & Positive & {$[23,42]$} \\
\hline EnP2: traffic improvement & Road widening area & Positive & [22] \\
\hline EnP3: entertainment facility improvement & Public activity spaces added & Positive & {$[22,24]$} \\
\hline EnP4: public facility improvement & Number of car parking provisions & Positive & [22] \\
\hline EnP5: safety facility improvement & $\begin{array}{l}\text { Number of Closed Circuit } \\
\text { Televisions (CCTVs) added }\end{array}$ & Positive & [18] \\
\hline EnP6: additional facility improvement & Number of car shed renovations & Positive & [41] \\
\hline \multicolumn{4}{|c|}{ Building performance $(B P)$} \\
\hline$B P 1$ : building renewal & Renewal building areas & Positive & {$[1,24]$} \\
\hline BP2: building facilities & $\begin{array}{l}\text { Number of house auxiliary } \\
\text { facilities added }\end{array}$ & Positive & Interview \\
\hline
\end{tabular}

\subsection{Weighting Values between Indicators through AHP Method}

The AHP is a very popular and widely used method for the weight elicitation of attributes in most MCDM methods [45]. The procedures for deriving weighting values between 13 indicators for neighborhood renewal projects by using the AHP method are summarized as follows.

\subsubsection{Normalization for All Indicators}

As the selected indicators have different dimensions and magnitudes, normalization is needed for converting all indicators into similar measurement scales. Assume there are $n$ independent indicators for neighborhood renewal project evaluation of $m$ samples of old neighborhoods. A Min-Max rescaling method is used to normalize the positive indicators with the following Equation (1) and negative indicators with Equation (2). For the positive indicators, a larger value represents better performance, while for the negative indicators, a smaller value represents better performance:

$$
Y_{i j}=\frac{X_{i j}-\operatorname{Min}_{j}\left(X_{i j}\right)}{\operatorname{Max}_{j}\left(X_{i j}\right)-\operatorname{Min}_{j}\left(X_{i j}\right)},
$$




$$
Y_{i j}=\frac{\operatorname{Max}_{j}\left(X_{i j}\right)-X_{i j}}{\operatorname{Max}_{j}\left(X_{i j}\right)-\operatorname{Min}_{j}\left(X_{i j}\right)},
$$

where $X_{i j}$ represents the original value of the indicator $i$ for the sample old neighborhood $j$, and $Y_{i j}$ represents the normalized value of the indicator $X_{i j}$.

\subsubsection{AHP Value for Individual Indicators}

The judgment matrix in the neighborhood renewal projects evaluation model reflects the relative importance of each indicator, as demonstrated in Equation (3):

$$
A_{u}=\left(a_{i j}\right)_{n \times n}=\left(\begin{array}{ccc}
1 & \cdots & a_{1 n} \\
\vdots & \ddots & \vdots \\
a_{n 1} & \cdots & 1
\end{array}\right)
$$

where $A_{u}$ is the judgment matrix, and $a_{i j}$ is the relative importance of indicator $i$ to indicator $j$, which ranges from 1 to 9. The scale of relative importance is shown in Table 4 according to Saaty [46].

Table 4. Scale of relative importance.

\begin{tabular}{cc}
\hline Intensity of Importance & Definition \\
\hline 1 & Equal importance \\
2 & Weak \\
3 & Moderate importance \\
4 & Moderate plus \\
5 & Strong importance \\
6 & Strong plus \\
7 & Very strong or demonstrated importance \\
8 & Very, very strong \\
9 & Extreme importance \\
\hline
\end{tabular}

For example, when $a_{i}$ is significantly more important than $a_{j}, a_{i j}$ is set to 9 , and $a_{j i}$ is set to $1 / 9$. Then, the weights $(w)$ of the indicators can be calculated from Equation (4):

$$
w_{i}=\frac{M_{i}}{\sum_{i=1}^{n} M_{i}}
$$

where

$$
M_{i}=\sqrt[n]{\prod_{j=1}^{n} a_{i j}}
$$

For computing the consistency ratio (CR), the following Equation (5) is applied:

$$
\mathrm{CR}=\frac{C I}{R I},
$$

where $C I$ represents the consistency index computed according to $C I=\left(\lambda_{\max }-n\right) /(n-1), n$ is the size of the matrix, and $\lambda_{\max }$ is the largest eigenvalue of the judgment matrix, which can be calculated from Equation (6). Equation (6) is

$$
\lambda_{\max }=\sum_{i=1}^{n} \frac{\sum_{j=1}^{n} a_{i j} w_{i}}{n w_{i}} .
$$

The $\mathrm{CR}$ is used to evaluate the sensitivity and consistency of the judgment matrix. According to Saaty (2008), if the CR is $>0.1$, then the judgment matrix is unreasonable and must be redetermined [46]. 


\subsection{Performance Evaluation for Neighborhood Renewal Projects through the TOPSIS Method}

TOPSIS was chosen to conduct the relative performance evaluation of multiple neighborhood renewal projects. TOPSIS can use attribute data in their entirety and offer a cardinal ranking of options and does not require attribute preferences to be independent compared to other multiple criteria models [29]. It is a method based on how close a limited number of evaluation objectives are to the idealized target. The method is used to evaluate, rank, and compare sample neighborhood renewal projects with the above criteria and indicators. The procedures for applying the TOPSIS method are described as follows.

\subsubsection{Normalization for All Indicators}

The process of normalization was addressed in the above Section 2.3.1.

\subsubsection{Weighted Values of Normalization Indicators}

The weighted value of the normalized indicator $\left(r_{i j}\right)$ is calculated by the following equations:

$$
r_{i j}=w_{i} Y_{i m}
$$

where $w_{i}$ is the weight of the indicators, and $Y_{i m}$ is the normalized value of indicators, which was defined in Equations (1), (2) and (4).

\subsubsection{The Ideal and the Negative Ideal Points}

The ideal point $\left(A^{+}\right)$is a composite of the best performance values of a sample old neighborhood across all indicators, while the negative ideal point $\left(A^{-}\right)$is a composite of the worst performance values. They are determined by the following equations (separately):

$$
\begin{aligned}
& A^{+}=\left\{r_{1}^{+}, r_{2}^{+}, r_{n}^{+}\right\}, \\
& A^{-}=\left\{r_{1}^{-}, r_{2}^{-}, r_{n}^{-}\right\},
\end{aligned}
$$

where

$$
\begin{aligned}
& r_{j}^{+}=\left\{\begin{array}{l}
\max _{j}\left\{r_{i j}\right\} \text { if } i \text { is a positive indicator } \\
\min _{j}\left\{r_{i j}\right\} \text { if } i \text { is a negative indicator }
\end{array},\right. \\
& r_{j}^{-}=\left\{\begin{array}{l}
\max _{j}\left\{r_{i j}\right\} \text { if } i \text { is a negative indicator } \\
\min _{j}\left\{r_{i j}\right\} \text { if } i \text { is a positive indicator }
\end{array} .\right.
\end{aligned}
$$

\subsubsection{Euclidean Distances from a Sample Old Neighborhood $j$ to the Ideal Point}

The Euclidean distances from a sample old neighborhood $j$ to the ideal point $\left(D^{+}\right)$and negative ideal point $\left(D^{-}\right)$are calculated by the following equations:

$$
\begin{aligned}
& D_{j}^{+}=\sqrt{\sum_{j=1}^{n}\left(r_{j}^{+}-r_{i j}\right)^{2}}, j=1,2, \ldots, m, \\
& D_{j}^{-}=\sqrt{\sum_{j=1}^{n}\left(r_{i j}-r_{j}^{-}\right)^{2}}, j=1,2, \ldots, m .
\end{aligned}
$$

\subsubsection{Computation of the Closeness Coefficient}

The value of the closeness coefficient $\left(C_{i}\right)$ is used to indicate the relative closeness of a particular sample old neighborhood $j$ to the negative ideal point. A larger value of closeness indicates better 
performance of a neighborhood renewal project, because a longer distance to the negative ideal point presents a better assessment result [29]:

$$
C_{j}=\frac{D_{j}^{-}}{D_{j}^{+}+D_{j}^{-}}
$$

The final score of the neighborhood renewal projects and their rankings is based on their performance level. Following the above TOPSIS procedures, the sample neighborhood renewal projects can be ranked in descending order based on their closeness coefficients. $C_{S P}, C_{E c P}, C_{E n P}$, and $C_{B P}$ are used to represent the performance score in the social, economic, environmental, and building dimensions, respectively. In addition, the total performance $C_{\text {Total }}$ for the neighborhood renewal projects is calculated by Equation (15):

$$
C_{\text {Total }}=C_{S P}+C_{E c P}+C_{E n P}+C_{B P}
$$

\section{Case Study}

\subsection{Background of ONR Projects in China}

According to data analysis from the National Bureau of Statistics and the Ministry of Housing and Urban-Rural Development, there are about 160,000 old neighborhoods in China with a residential construction area of 800 million square meters influencing more than 42 million families (i.e., $10 \%$ of the urban population) [27]. In order to solve the problem of inadequate and imbalanced urban development and achieve people's longing for a better life, the Chinese government vigorously promotes the request for ONRs. Many conferences and plans are declared to speed up and orderly promote ONR projects, such as the National Conference on City Works in 2015 organized by the Central Committee of the Communist Party of China (CCCPC), the "13th Five-Year Plan" in 2016, and the "two sessions" (the National People's Congress (NPC) and the Chinese People's Political Consultative Conference (CPPCC) in 2018 and 2019). Accordingly, many local governments make grand plans committing to renewal projects. For example, Beijing has completed 1678 ONR projects during the "12th Five-Year Plan" period (i.e., 2010-2015). In addition, 15 cities (e.g., Xiamen, Shenyang, and Liuzhou) were chosen by the Ministry of Housing and Urban-Rural Development to be the pilots in order to explore new renewal models and provide repeatable experiences for the whole country.

The implementation of ONR projects normally focuses on infrastructure development, enables the extension of building lifespans, and increases the neighborhood environment [13]. Rather than tearing everything down and building new buildings, the ONR projects have been carried out with the idea of "organic renewal" or "micro-transformation" [13,47]. This form of redevelopment emphasizes partial remediation and mainly focuses on the built environment such as the renewal of living space, pipeline equipment, façade decoration, and parking spaces [27]. Physical rehabilitation in a specific technical field is a common type of ONR, e.g., energy savings modifications in an old building, sponge-style renewal of rainwater systems, green transformation for the environment, and aging-friendly redevelopment for old people in a neighborhood $[4,48,49]$. Other ONR practices related to community governance are also important parts of projects, such as rebuilding a harmonious neighborhood atmosphere, improving the operation and management of the community, and advocating for residents to participate in the ONR projects [13].

The whole process of ONR projects is shown in Figure 2. The city and district governments are responsible for the selection of the renewal projects, providing the funds, and developing renewal plans with specific responsibilities at different stages [50]. Sub-district offices (Jiedao in Chinese) are in charge of the whole organization during the implementation stage and are responsible for directly communicating with residents. After the construction of a renewal project, the district real estate department is responsible for quality acceptance, emphasizing the physical environment $[13,27]$. Other 
stakeholders such as the planning units, construction units, supervision units, and residents are encouraged to participate in different stages of the renewal process.

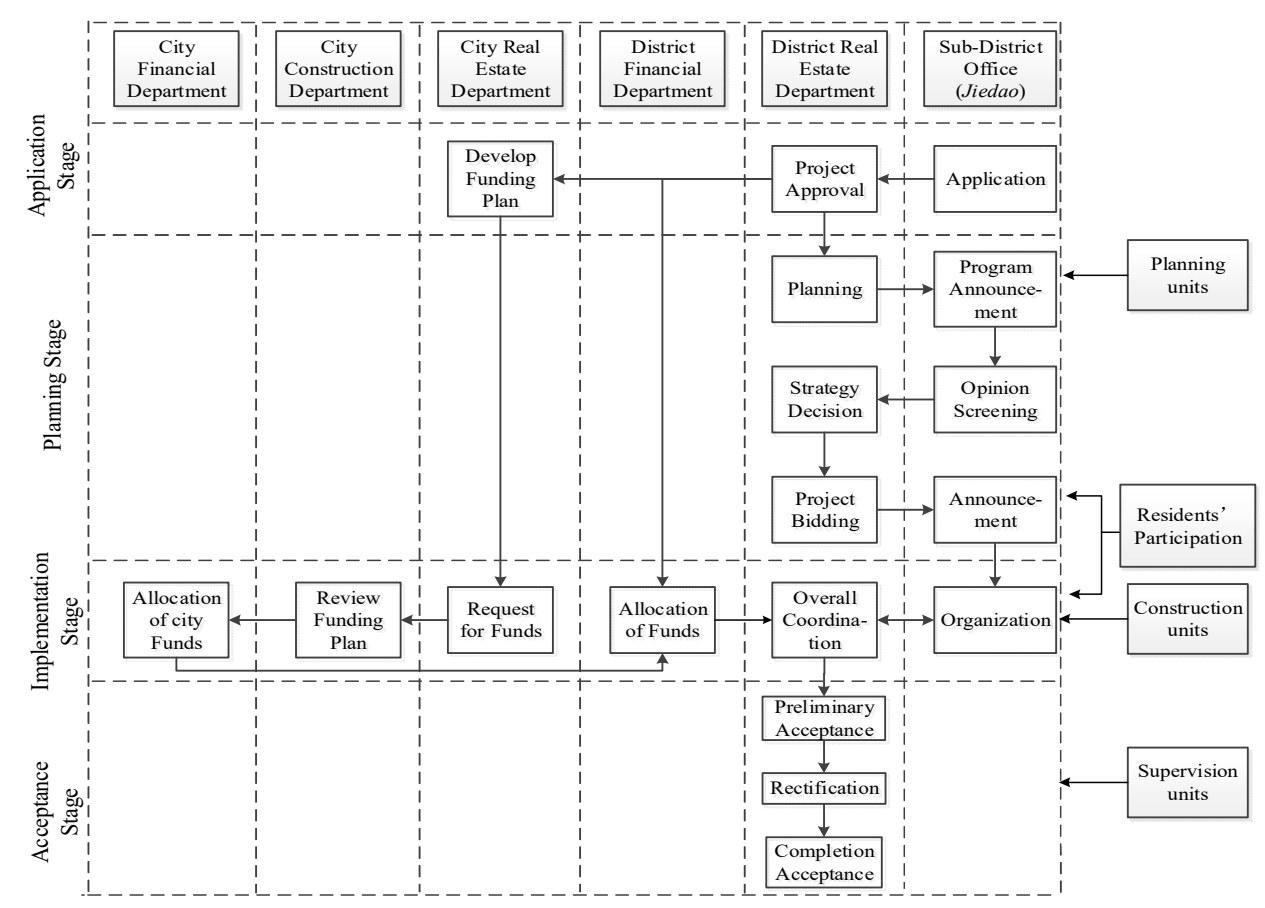

Figure 2. The whole process of a typical ONR project.

\subsection{Selection of ONR Projects in Nanjing}

Nanjing, a city in eastern China, is the capital of Jiangsu Province and is about $300 \mathrm{~km}$ to the west of Shanghai. The Nanjing government strongly supports the ONR plan, and the government has already renewed 1009 old neighborhoods since 2006. In 2017, 240 old neighborhoods in Nanjing were renewed, and 1900 buildings with 72,000 families were involved. Gulou District, one of the central districts of Nanjing, has had the largest number of ONR projects among the six districts: 99 neighborhoods in Gulou District were renewed involving 610 buildings and 23,858 families, which accounts for $41.25 \%$ of total ONR projects and 33.14\% of involved families in 2017.

Therefore, 18 old neighborhoods were randomly selected in Gulou District in Nanjing as the samples for ONR project evaluation (the locations are shown in Figure 3). All of the 18 old neighborhoods began renewal in May 2017, and they were completed at the end of the same year. The renewal works were mainly focused on the physical renewal of buildings, facilities, and environments in the neighborhood. The budget for each neighborhood was around $450 \mathrm{yuan} / \mathrm{m}^{2}$, which completely came from the government. In order to be objective and quantitative, the data were collected directly from the government in 2018. Details of the source for each indicator can be found in Table 5 .

Table 5. Sources of the primary data.

\begin{tabular}{|c|c|c|}
\hline Indicator Information & Raw Data & Source \\
\hline$B P 2$ & Government statistic yearbook & $\begin{array}{c}\text { Housing Security and Real Estate Bureau } \\
\text { of Nanjing }\end{array}$ \\
\hline $\begin{array}{l}\text { BP1, SP1, EnP1, EnP2, } \\
\text { EnP3, EnP4, EnP5, EnP6 }\end{array}$ & Governmental report & $\begin{array}{l}\text { ONR Office of Building Real Estate and } \\
\text { Transportation Bureau in Gulou District }\end{array}$ \\
\hline$S P 2, S P 3, E c P 1$ & Government document & $\begin{array}{l}\text { Subdistrict office and community center } \\
\text { in Gulou District }\end{array}$ \\
\hline$E c P 2$ & Online report & Local building manager in Gulou District \\
\hline
\end{tabular}




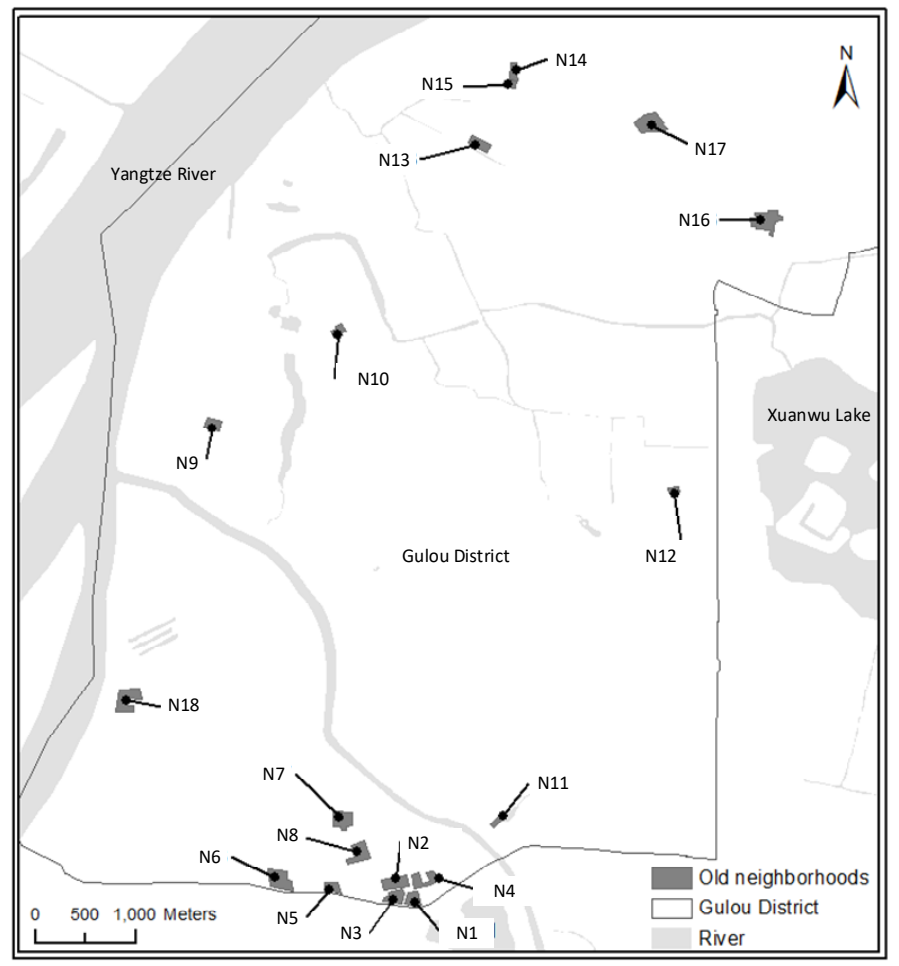

Figure 3. Location of selected old neighborhoods in Gulou District, Nanjing.

\subsection{Results}

\subsubsection{Weighting Results between Each Indicators}

The weighting results between each indicators were obtained from experts' opinions through the AHP method with Equations (3)-(6). Experts were asked to grade each indicator, and the average weights given by eight experts were used as the final weights for the indicators. As shown in Figure 4, indicators from building performance had the highest importance, followed by environmental performance. This represents that building renewal and environment renewal were the priority for ONR projects. Moreover, the three highest weights were $B P 1, B P 2$, and EnP1, while the three lowest were EnP3, EnP6, and EnP5.

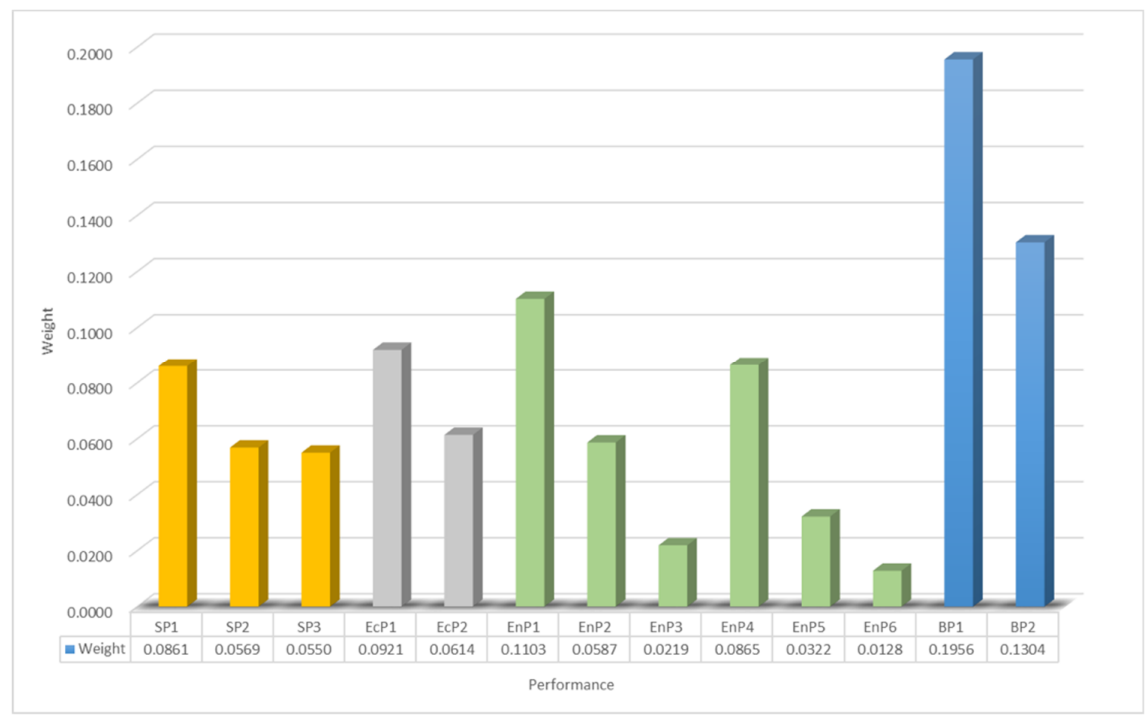

Figure 4. Weight value for each indicator. 


\subsubsection{TOPSIS Results}

After getting the weight for each indicator, the relative performances of sample ONR projects were utilized by the TOPSIS technique with Equations (1) and (2) and (7)-(15). The performance results are illustrated in Table 6 with four performance dimensions. For the results of social aspects, N8 had the best performance, whereas N5 ranked the worst. N1 had the highest score for economic and environmental performance, while N11 had the worst. In terms of the building aspect, N18 obtained the highest score, and N11 obtained the worst condition. The average level of economic conditions was the highest among the four dimensions followed by social aspects, whereas environmental performance presented the worst.

Table 6. Performance assessment results from the technique for order preference through similarity to an ideal solution (TOPSIS).

\begin{tabular}{ccccccccc}
\hline Old Neighborhood & $C_{S P}$ & Rank & $C_{E c P}$ & Rank & $C_{E n P}$ & Rank & $C_{B P}$ & Rank \\
\hline N1 & 0.4468 & 15 & 1.0000 & 1 & 0.5448 & 1 & 0.5411 & 7 \\
N2 & 0.4082 & 17 & 0.8093 & 4 & 0.3892 & 11 & 0.5331 & 8 \\
N3 & 0.4967 & 12 & 0.7679 & 5 & 0.3457 & 13 & 0.5901 & 4 \\
N4 & 0.5097 & 10 & 0.7152 & 6 & 0.2790 & 14 & 0.3497 & 11 \\
N5 & 0.2578 & 18 & 0.1353 & 17 & 0.2258 & 16 & 0.4922 & 9 \\
N6 & 0.5884 & 7 & 0.6264 & 10 & 0.1488 & 17 & 0.6446 & 3 \\
N7 & 0.6177 & 4 & 0.8363 & 3 & 0.4234 & 7 & 0.5767 & 5 \\
N8 & 0.6425 & 1 & 0.8370 & 2 & 0.3968 & 9 & 0.2153 & 13 \\
N9 & 0.5912 & 6 & 0.3845 & 12 & 0.4877 & 2 & 0.1738 & 16 \\
N10 & 0.6253 & 3 & 0.6991 & 7 & 0.2547 & 15 & 0.1875 & 14 \\
N11 & 0.4292 & 16 & 0.0779 & 18 & 0.1036 & 18 & 0.1022 & 18 \\
N12 & 0.5842 & 8 & 0.3690 & 13 & 0.4805 & 3 & 0.1833 & 15 \\
N13 & 0.5925 & 5 & 0.2278 & 16 & 0.4415 & 5 & 0.3611 & 10 \\
N14 & 0.5081 & 11 & 0.3026 & 14 & 0.4261 & 6 & 0.3442 & 12 \\
N15 & 0.6343 & 2 & 0.3026 & 14 & 0.3928 & 10 & 0.1642 & 17 \\
N16 & 0.5195 & 9 & 0.6453 & 9 & 0.4061 & 8 & 0.5616 & 6 \\
N17 & 0.4709 & 13 & 0.6893 & 8 & 0.3812 & 12 & 0.6697 & 2 \\
N18 & 0.4549 & 14 & 0.6000 & 11 & 0.4664 & 4 & 0.9589 & 1 \\
Average & 0.5210 & & 0.5570 & & 0.3663 & & 0.4250 & \\
\hline
\end{tabular}

The total performance of the ONR projects was calculated based on the above four dimensions, as demonstrated in Figure 5, with their ranks in descending order. The results gave an average score of the sample 18 ONR projects a value of 1.8692 . The range of the performance score was between zero and four. Thus, considering the value range of the performance score, four grades of the overall score could be classified, namely the highest (3 4), high (2 3), low (1 2), and the lowest (0 1). Then the number of ONR projects in each category could be derived as the following categories: $50 \%$ with high performance, $44.44 \%$ with low performance, and $5.56 \%$ with the lowest performance. Although there were no ONR projects that reached the highest performance, half of the ONR projects showed good performance. Therefore, the overall performance of ONR projects was at a relatively moderate level. 


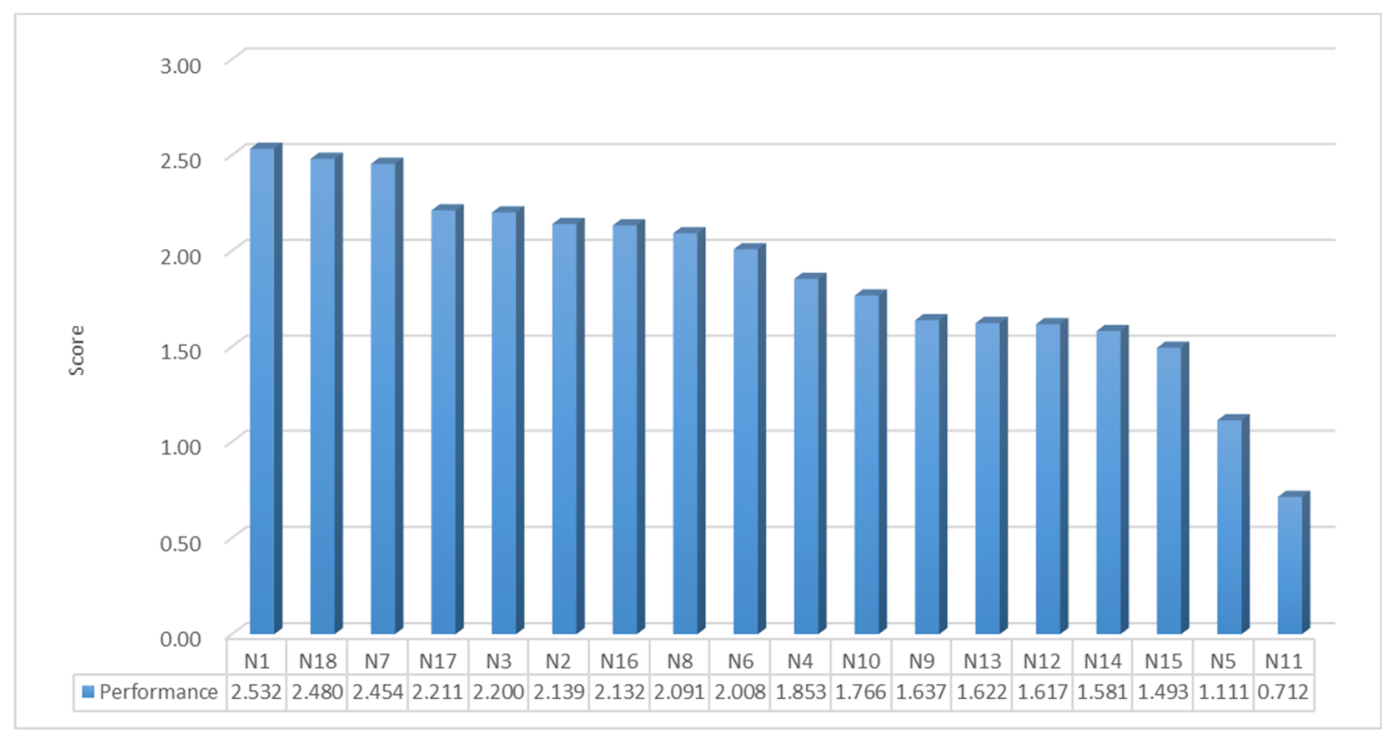

Figure 5. Performance score for 18 ONR projects and their rankings.

\section{Discussions}

\subsection{Differences in Renewal Performance}

The results showed that the overall performance of the ONR projects was at a relatively moderate level, with half of the projects resulting in high performance. The maximum total performance score of the sample projects was 2.5327 , while the lowest was 0.7128 . The maximum score was over 3.5 times higher than the minimum one, which showed a significant difference in performance between these ONR projects. In detail, N1 was the project comparatively with the most performance in the study area. According to Table 6, N1 ranked well in economic, environmental, and building dimensions, but had a lower score in social aspects. This was mainly due to the higher housing price rise rate ( $E c P 2)$, effectively introduced property management $\left(E_{c} P 1\right)$, and higher resident complaints $(S P 3)$. Although the physical renewal of N1 went well, the satisfaction of the residents was not as expected. N11 presented the poorest performance in the renewal process: the result was the consequence of characteristics from all dimensions. The reason might be the various backgrounds of these old neighborhoods, including location, history, and people. This indicated an unbalanced development of these neighborhoods, and each old neighborhood may need its own plan for regeneration with respect to diversity.

The results can also provide references for policy-makers for specific old neighborhoods, as the performance of each ONR project can be found in the evaluation. For example, N18 presented a better situation in building and environmental aspects, but showed relatively worse performance in social and economic dimensions. This finding provides reminders for decision-makers to care about such issues in this neighborhood. Referring to the data of the indicators for N18, although the building and environmental situation improved a lot, both the change rate of crime frequency and housing values had low scores. Therefore, more attention should be focused on this problem. Further investigation of the population structure, geographic conditions, etc., in this neighborhood can be carried out in order to solve the problem.

\subsection{Priority of Renewal Strategies for Multiple Neighborhoods}

In order to provide a priority of strategies for each neighborhood, further comparisons were conducted with the scores of the ONR projects. Referring to the neighborhood renewal policy and process in China (Section 3.1), physical rehabilitation was the main purpose of the ONR projects, which were fully funded and implemented by the government. The social and economic aspects were mainly the outcomes or effects of the ONR projects. Thus, we divided the performance into two 
parts: social-economic performance and physical performance. The socioeconomic performance was calculated by $C_{S P}$ and $C_{E c P}$, while the physical performance came from $C_{E n P}$ and $C_{B P}$. Therefore, a decision-making matrix could be drawn (Figure 6).

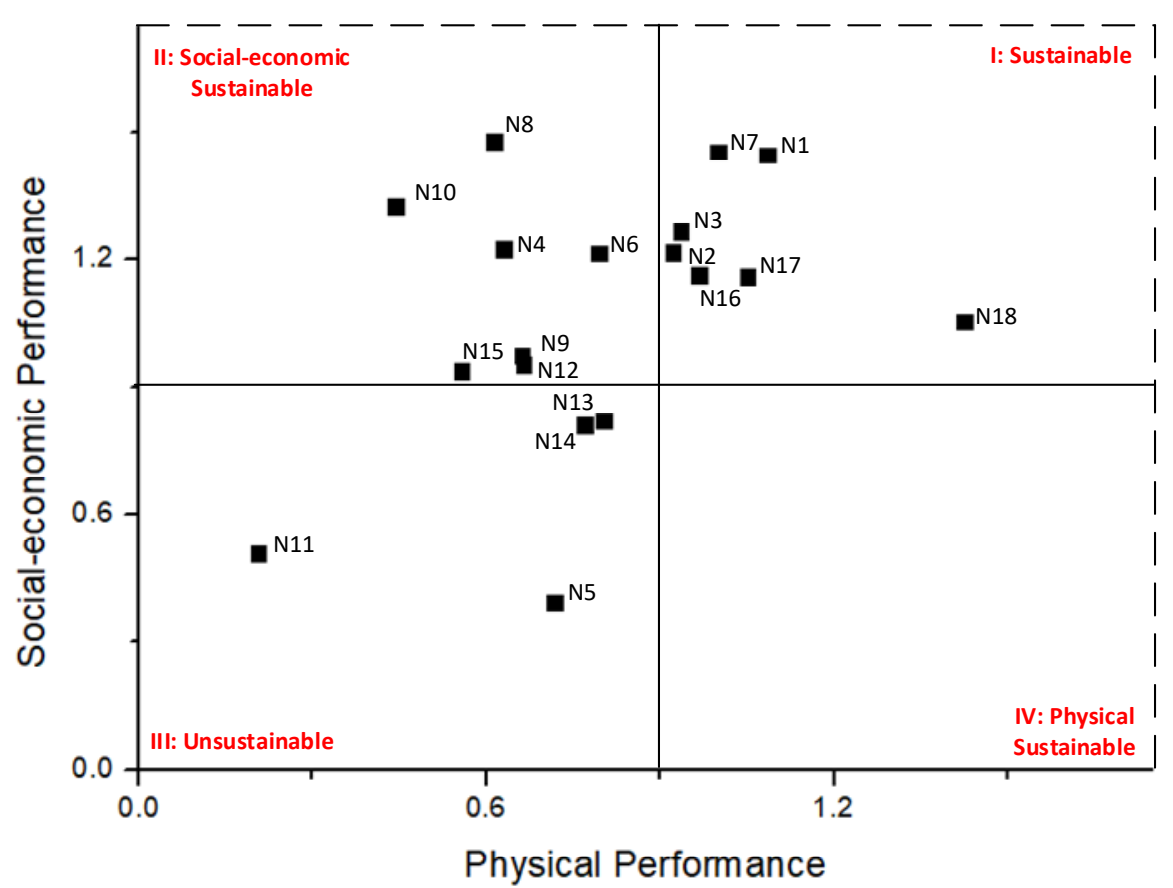

Figure 6. Decision-making matrix.

As demonstrated in Figure 6, no ONR projects were in quadrant IV. Seven ONR projects were categorized into quadrant I, which showed better performance in both physical and socioeconomic aspects. These neighborhoods could be considered to be high-performance for sustainable development. Further improvement strategies for these neighborhoods are recommended through referring to their own specific problems with considerations about other factors, such as history, property, or the operation of the neighborhood.

Seven ONR projects belonged to quadrant II. These neighborhoods were better in social-economic performance but relatively worse in physical condition. According to the data of the indicators and interviews with government officers, one reason might be the reduction of green spaces. Normally, the old neighborhood itself has a small public area without parking spaces, which results in random parking and affects neighborhood relations [13]. In order to solve that problem during the renewal planning, some neighborhoods reduced green spaces to create additional spaces for parking and public activities. Although this design solved the parking problem and gained residents' acceptance, it is not a sustainable residential development in terms of the environment and it will lead to a decline in the quality of neighborhood life in the long run. Deep investigations can be conducted in these neighborhoods to find other detailed problems of the buildings and facilities. The strategies for them may include continually upgrading buildings and facilities, increasing green space, and improving the community environment.

$\mathrm{N} 5, \mathrm{~N} 11, \mathrm{~N} 13$, and N14 were four neighborhoods with worse performance, as shown in quadrant III. This implies that continuous renewal may be a priority strategy for these neighborhoods in the long run. Neighborhood renewal helps to improve both situations of physical decay and social-economic performance, which is provided by considering every aspect of sustainable development [24]. Moreover, although the renewal process is guided by the government, the participation of the residents is also important. Residents are the direct or indirect beneficiaries of the neighborhood renewal projects [41]. The current needs for neighborhood renewal can be recognized most accurately by the residents. 
During the renewal process, various conflicts regarding the interests of the residents are present. Residents that participate can directly search for alternative solutions to solve or minimize conflict [51]. Thus, better panning and successful implementation of ONR projects can be obtained.

Besides, as mentioned in Section 1, before the ONRs, most of the old neighborhoods in China did not have property management, which led to a dirty environment of cluttered corridors, pit lanes, and a high theft rate [15]. Introducing property management is the top priority in achieving long-term governance and promoting sustainability in ONR projects [13]. It is encouraged to establish a batch of public property service companies financially supported by the government. Despite the highest economic performance $\left(C_{E c P}=0.5570\right)$, it is still not easy to introduce a property management company into old neighborhoods. One reason is that the old neighborhoods face high management costs due to small spaces, overpopulation, and a high aging rate [52]. The other reason is that the fee standards for property management services are very low in old neighborhoods, since the residents living in old neighborhoods usually have low income [1]. The property management companies usually gain little or no profit from old neighborhoods. Some neighborhoods in ONR projects, such as N1 to N4, which are close to each other, were merged into a larger neighborhood to attract professional property management companies. All of the neighborhoods in quadrant IV are still searching for a solution after their ONRs. Necessary policies and subsidies from the government should be provided to encourage property companies or neighborhood organizations to join the management of old neighborhoods [53].

\subsection{Suggestions for Future Neighborhood Renewal}

The results and discussions of the relative performance evaluations of neighborhood renewal projects can serve as references for decision-makers, and some suggestions can also be provided.

Better renewal performance and sustainable development of the neighborhoods need the participation of all stakeholders, both in the public and private sectors. A multiple principal-agent framework should be built during the renewal process. Residents can be the initial principals, and the government serves as the agent for the residents. Corporations and social organizations can be the agents for both the government and the residents. This will help to fulfill the needs of the residents, encourage the participation of the private sector, and relieve the government's financial pressure.

Thus, the value preferences, behavior choices, and interaction models for both sides should be clarified first. Then, further improvement of the neighborhood autonomy level should be provided, such as establishing a neighborhood residents database, broadening participation channels, and providing guidelines for proper participation and training courses for neighborhood workers and volunteers [4]. The potential of private corporations should be used, and they should be encouraged to invest in neighborhood renewal projects through modern financial models such as a public-private partnership. Therefore, regulated funding from both the public and private sectors can be implemented to enable a sustainable funding system in neighborhood renewal [31,54]. Moreover, it is also encouraged to actively guide, expand, and further strengthen the development of nongovernmental organizations. Lastly, relevant polices and standards should be established to ensure the efficient implementation of the principal-agent framework.

Besides, the actual situation of neighborhoods varies from place to place, as different neighborhoods have different backgrounds of history, people, and culture. Full investigations of local conditions, detailed planning, and full respect for the diversity of neighborhood before the renewal are really needed. It helps to accurately understand the needs of the residents and the actual situation of the neighborhood in different regions and types [14]. A design that covers a comprehensive consideration of a variety of factors and strives to achieve overall design refinement is suggested [15]. Multiprogram management measures, such as prescribed renewal plus optional renewal, are also suggested to be provided with respect to different needs and local conditions. 


\section{Conclusions}

Performance evaluations for neighborhood renewal projects are necessary and important for decision-making. Existing studies have rarely focused on the assessment of neighborhood renewal projects. Taking the ONR projects in China as an example, this paper developed a systematic framework for the relative performance evaluations of multiple neighborhood renewal projects through a hybrid AHP-TOPSIS method. The evaluation indicators were chosen from social, economic, environmental, and building dimensions. The results showed relatively moderate levels of performance for the sample neighborhood renewal projects, and each neighborhood needs to choose a priority of strategies for its own characteristics in order to pursue sustainable development.

The evaluation results can help to reveal the strength and shortcomings of different neighborhood renewal projects. It also provides a decision matrix for the priority of strategies for specific neighborhoods in order to pursue the sustainability of renewal projects. The ranking of different neighborhood renewal projects can be used as a reference for project rewards or penalties. This will help to regulate the behavior of private units and encourage supervision by residents. Besides, the framework developed in this paper is also suitable for different neighborhoods in other cities or countries. The indicators and decision-making matrix are not fixed and can be altered to match the circumstances in distinct fields when considering particular contexts in applying performance evaluations in practice. Thus, various kinds of neighborhoods after renewal can be assessed and compared under the same framework. This is a supplement to existing urban renewal studies and provides references for sustainable urban/neighborhood renewal.

More extended work can be developed when large-scale sets of data are available and accessible to assess the performances of renewal projects. For example, acoustic emissions, resource consumption, and waste minimization can be considered in environmental performance evaluations when data are available. Moreover, the performance of a neighborhood renewal project may change with time, and performing regular evaluations is suggested for further comparisons in order to promote sustainable development.

Author Contributions: Conceptualization, D.L.; methodology, D.L. and S.Z.; validation, T.G.; investigation, J.Z. and S.Z.; data curation, S.Z.; writing - original draft preparation, S.Z.; writing-review and editing, D.L. and H.F.

Funding: This project was funded by the National Social Science Fund of China (No. 19BGL281), the National Key R\&D Program of China (No. 2018YFD1100202), the MOE Project of Humanities and Social Sciences (No. 17YJAZH038), the Social Science Project of Jiangsu Province (No. 18GLB002), the Postgraduate Research \& Practice Innovation Program of Jiangsu Province (No. KYCX17_0192, No. KYCX18_0203, and No. KYLX15_0095), and the Fundamental Research Funds for the Central Universities (No. 2242019K40063).

Conflicts of Interest: The authors declare that they have no competing interests.

\section{References}

1. Zheng, H.W.; Shen, G.Q.P.; Song, Y.; Sun, B.; Hong, J. Neighborhood sustainability in urban renewal: An assessment framework. Environ. Plan. B Urban Anal. City Sci. 2017, 44, 903-924. [CrossRef]

2. Ryu, H.; Lee, J.S.; Lee, S. Participatory Neighborhood Revitalization Effects on Social Capital: Evidence from Community Building Projects in Seoul. J. Urban Plan. Dev. 2018, 144, 04017025. [CrossRef]

3. Wu, F.; He, S. Changes in traditional urban areas and impacts of urban redevelopment: A case study of three neighbourhoods in Nanjing, China. Tijdschr. Econ. Soc. Geogr. 2005, 96, 75-95. [CrossRef]

4. Tin, W.J.; Lee, S.H. Development of neighbourhood renewal in Malaysia through case study for middle income households in New Village Jinjang, Kuala Lumpur. Sustain. Cities Soc. 2017, 32, 191-201. [CrossRef]

5. Teernstra, A.B.; Pinkster, F.M. Participation in neighbourhood regeneration: achievements of residents in a Dutch disadvantaged neighbourhood. Urban Res. Pract. 2016, 9, 56-79. [CrossRef]

6. Lelévrier, C. Social mix neighbourhood policies and social interaction: The experience of newcomers in three new renewal developments in France. Cities 2013, 35, 409-416. [CrossRef]

7. Rosenthal, S.S. Old homes, externalities, and poor neighborhoods. A model of urban decline and renewal. J. Urban Econ. 2008, 63, 816-840. [CrossRef] 
8. Auerbach, G. Urban politics and public policy—Looking back and going forward: "Project Renewal" in one Israeli city. Cities 2013, 31, 197-207. [CrossRef]

9. Koramaz, T.K. Housing Renewal Sites and Spatial Features of Deterioration and Deprivation in Istanbul's Historic Peninsula. J. Urban Plan. Dev. 2018, 144, 4018003. [CrossRef]

10. Hindhede, A.L. Neighbourhood renewal, participation, and social capital in deprived areas: Unintended consequences in a Nordic context. Eur. Soc. 2016, 18, 535-559. [CrossRef]

11. Nakazato, H.; Lim, S. Community rebuilding processes in a disaster-damaged area through community currency: The pilot project of Domo in Kamaishi, Japan. Disaster Prev. Manag. 2017, 26, 79-93. [CrossRef]

12. Shi, Q.; Yu, T.; Zuo, J.; Lai, X. Reprint of: Challenges of developing sustainable neighborhoods in China. J. Clean. Prod. 2017, 163, S42-S53. [CrossRef]

13. Cai, Y.; Yang, X.; Li, D. "Micro-transformation": the renewal method of old urban community. Urban Dev. Stud. 2017, 24, 29-34. (In Chinese)

14. Wang, H.; Shen, Q.; Tang, B.S.; Lu, C.; Peng, Y.; Tang, L.Y. A framework of decision-making factors and supporting information for facilitating sustainable site planning in urban renewal projects. Cities 2014, 40, 44-55. [CrossRef]

15. Huang, J.; Sun, Q. The triple dilemma of urban old community governance-Taking Nanjing J community environmental remediation action as an example. Wuhan Univ. Technol. Sci. Ed. 2016, 29, 28-33. (In Chinese)

16. Cahantimur, A.I.; Öztürk, R.B.; Öztürk, A.C. Securing land for urban transformation through sustainable brownfield regeneration-The case of Eskişehir, turkey. Environ. Urban. 2010, 22, 241-258. [CrossRef]

17. Xu, K.; Shen, G.Q.; Liu, G.; Martek, I. Demolition of existing buildings in urban renewal projects: A decision support system in the China context. Sustainability 2019, 11, 491. [CrossRef]

18. Almeida, C.P.; Ramos, A.F.; Silva, J.M. Sustainability assessment of building rehabilitation actions in old urban centres. Sustain. Cities Soc. 2018, 36, 378-385. [CrossRef]

19. Sharifi, A.; Murayama, A. A critical review of seven selected neighborhood sustainability assessment tools. Environ. Impact Assess. Rev. 2013, 38, 73-87. [CrossRef]

20. Tam, V.W.Y.; Karimipour, H.; Le, K.N.; Wang, J. Green neighbourhood: Review on the international assessment systems. Renew. Sustain. Energy Rev. 2018, 82, 689-699. [CrossRef]

21. Zheng, H.W.; Shen, G.Q.; Wang, H. A review of recent studies on sustainable urban renewal. Habitat Int. 2014, 41, 272-279. [CrossRef]

22. Hemphill, L.; Berry, J.; McGreal, S. An indicator-based approach to measuring sustainable urban regeneration performance: Part 1, conceptual foundations and methodological framework. Urban Stud. 2004, 41, 725-755. [CrossRef]

23. Peng, C.; Ming, T.; Gui, J.; Tao, Y.; Peng, Z. Numerical analysis on the thermal environment of an old city district during urban renewal. Energy Build. 2015, 89, 18-31. [CrossRef]

24. Riera Pérez, M.G.; Laprise, M.; Rey, E. Fostering sustainable urban renewal at the neighborhood scale with a spatial decision support system. Sustain. Cities Soc. 2018, 38, 440-451. [CrossRef]

25. Dezhi, L.; Yanchao, C.; Hongxia, C.; Kai, G.; Chi-Man Hui, E.; Yang, J. Assessing the integrated sustainability of a public rental housing project from the perspective of complex eco-system. Habitat Int. 2016, 53, 546-555. [CrossRef]

26. McCartney, G.; Hearty, W.; Taulbut, M.; Mitchell, R.; Dryden, R.; Collins, C. Regeneration and health: A structured, rapid literature review. Public Health 2017, 148, 69-87. [CrossRef] [PubMed]

27. Liang, C.; Li, C. Mian practice and thoughs on comprehensive renewal of old community in Beijing. Constr. Sci. Technol. 2016, 9, 20-23. (In Chinese)

28. Behzadian, M.; Khanmohammadi Otaghsara, S.; Yazdani, M.; Ignatius, J. A state-of the-art survey of TOPSIS applications. Expert Syst. Appl. 2012, 39, 13051-13069. [CrossRef]

29. Lai, Y.J.; Liu, T.Y.; Hwang, C.L. TOPSIS for MODM. Eur. J. Oper. Res. 1994, 76, 486-500. [CrossRef]

30. Karatas, A.; El-Rayes, K. Evaluating the performance of sustainable development in urban neighborhoods based on the feedback of multiple stakeholders. Sustain. Cities Soc. 2015, 14, 374-382. [CrossRef]

31. Yang, Z.; Zhong, L. Learning from the "residential community" consciousness training of community governance in Taiwan: reflection on the community governance of old residential cistrict of Chengdu. Mordern Urban Res. 2017, 9, 65-71. (In Chinese)

32. Power, A. Does demolition or refurbishment of old and inefficient homes help to increase our environmental, social and economic viability? Energy Policy 2008, 36, 4487-4501. [CrossRef] 
33. Wang, M.; Li, Y.; Zhang, W.X.; He, C.H. The performance evaluation of urban renewal based on DEA method: Example in Xicheng Distric, Beijing. Urban Dev. Stud. 2011, 10, 90-96. (In Chinese)

34. Huang, N.; Cui, S.; Liu, Q.; Wen, C.; Chen, X. Study on the characteristics of community human settlements in Peri-urban area during urbanization: A case of Jimei distric, Xiamen city. Progess Geogr. 2012, 31, 750-760. (In Chinese)

35. Hwang, J.; Sampson, R.J. Divergent pathways of gentrification: Racial inequality and the social order of renewal in Chicago neighborhoods. Am. Sociol. Rev. 2014, 79, 726-751. [CrossRef]

36. Xu, J.; Lv, H.; Zou, X. Empirical evaluation on comprehensive benefits of reconstruction of old city-Take Chongqing's urban main road's reconstruction for example. J. Tech. Econ. Manag. 2015, 8, 118-122. (In Chinese)

37. Wang, A.; Hu, Y.; Li, L.; Liu, B. Group Decision Making Model of Urban Renewal Based on Sustainable Development: Public Participation Perspective. Procedia Eng. 2016, 145, 1509-1517. [CrossRef]

38. Della Spina, L.; Lorè, I.; Scrivo, R.; Viglianisi, A. An Integrated Assessment Approach as a Decision Support System for Urban Planning and Urban Regeneration Policies. Buildings 2017, 7, 85. [CrossRef]

39. Trop, T. Social impact assessment of rebuilding an urban neighborhood: A case study of a demolition and reconstruction project in Petah Tikva, Israel. Sustainability. 2017, 9, 1076. [CrossRef]

40. Li, L.; Hong, G.; Wang, A.; Liu, B.; Li, Z. Evaluating the Performance of Public Involvement for Sustainable Urban Regeneration. Procedia Eng. 2016, 145, 1493-1500. [CrossRef]

41. Zhang, C.; Lu, B. Residential satisfaction in traditional and redeveloped inner city neighborhood: A tale of two neighborhoods in Beijing. Travel Behav. Soc. 2016, 5, 23-36. [CrossRef]

42. Huang, K.-H.; Pai, J.-T.; Liu, J.-H. Study of Performance Assessment for Urban Renewal Project in Taipei City. Int. Rev. Spat. Plan. Sustain. Dev. 2016, 4, 64-77. [CrossRef]

43. Allik, M.; Kearns, A. "There goes the fear": feelings of safety at home and in the neighborhood: The role of personal, social, and service factors. J. Community Psychol. 2017, 45, 543-563. [CrossRef]

44. Peng, Y.; Lai, Y.; Li, X.; Zhang, X. An alternative model for measuring the sustainability of urban regeneration: The way forward. J. Clean. Prod. 2015, 109, 76-83. [CrossRef]

45. Vaidya, O.S.; Kumar, S. Analytic hierarchy process: An overview of applications. Eur. J. Oper. Res. 2006, 169, 1-29. [CrossRef]

46. Saaty, T.L. Decision making with the analytic hierarchy process. Int. J. Serv. Sci. 2008, 1, 83. [CrossRef]

47. Wu, L. Rehabilitation in Beijing. Habitat Int. 1991, 15, 51-66.

48. Cho, M.; Kim, J. Coupling urban regeneration with age-friendliness: Neighborhood regeneration in Jangsu Village, Seoul. Cities 2016, 58, 107-114. [CrossRef]

49. Jia, H.; Wang, Z.; Zhen, X.; Clar, M.; Yu, S.L. China's sponge city construction: A discussion on technical approaches. Front. Environ. Sci. Eng. 2017, 11, 18. (In Chinese) [CrossRef]

50. Zhang, X.; Hu, J.; Yang, Q.; Lin, Y. Analysis and renewal strategy of old residential district. Urban Dev. Stud. 2017, 11, 88-92. (In Chinese)

51. Hong, Y. Resident participation in urban renewal: Focused on Sewoon Renewal Promotion Project and Kwun Tong Town Centre Project. Front. Archit. Res. 2018, 7, 197-210. [CrossRef]

52. He, S. Homeowner associations and neighborhood governance in Guangzhou, China. Eurasian Geogr. Econ. 2015, 56, 260-284. [CrossRef]

53. Wang, Y.; Li, J.; Zhang, G.; Li, Y.; Asare, M.H. Fuzzy evaluation of comprehensive benefit in urban renewal based on the perspective of core stakeholders. Habitat Int. 2017, 66, 163-170. [CrossRef]

54. Mavrodieva, A.V.; Daramita, R.I.F.; Arsono, A.Y.; Yawen, L.; Shaw, R. Role of civil society in sustainable urban renewal (Machizukuri) after the Kobe Earthquake. Sustainability 2019, 11, 335. [CrossRef]

(C) 2019 by the authors. Licensee MDPI, Basel, Switzerland. This article is an open access article distributed under the terms and conditions of the Creative Commons Attribution (CC BY) license (http://creativecommons.org/licenses/by/4.0/). 